\title{
ON STEVIĆ-SHARMA TYPE OPERATOR FROM THE BESOV SPACES INTO THE WEIGHTED-TYPE SPACE $H_{\mu}^{\infty}$
}

\author{
YONGMIN LIU AND YANYAN YU
}

Abstract. We completely describe the boundedness and compactness of Stević-Sharma type operator $T_{\psi_{1}, \psi_{2}, \varphi}$ from the Besov spaces $B_{p}(1<p<\infty)$ into the weighted-type space $H_{\mu}^{\infty}$ or the little weighted-type space $H_{\mu, 0}^{\infty}$.

Mathematics subject classification (2010): 47B38, 47B33, 46E15, 30H05.

Keywords and phrases: Besov space, weighted-type space, Stević-Sharma type operator.

\section{REFERENCES}

[1] J. Arazy, S. D. Fisher And J. Peetre, Möbius invariant function spaces, J. Reine Angew. Math. 363 (1985), 110-145.

[2] F. COlOnNA AND M. TJAnI, Weighted composition operators from the Besov spaces into the weighted-type space $H_{\mu}^{\infty}$, J. Math. Anal. Appl. 402, 2 (2013), 594-611.

[3] F. COLONNA AND M. TJANI, Operator norms and essential norms of weighted composition operators between Banach spaces of analytic functions, J. Math. Anal. Appl. 434, 1 (2016), 93-124.

[4] R. A. HibsChweILER AND N. PorTnOy, Composition followed by differentiation between Bergman and Hardy spaces, Rocky Mountain J. Math. 35, 3 (2005), 843-855.

[5] O. HYVÄRINEN AND I. NIEMINEN, Weighted composition followed by differentiation between Blochtype spaces, Rev. Mat. Complut. 27, 2 (2014), 641-656.

[6] S. G. KRANTZ AND S. STEVIĆ, On the iterated logarithmic Bloch space on the unit ball, Nonlinear Anal. TMA71, 5-6 (2009), 1772-1795.

[7] S. Li And S. STEvić, Composition followed by differentiation between Bloch type spaces, J. Comput. Anal. Appl. 9, 2 (2007), 195-205.

[8] S. Li AND S. STEVIĆ, Differentiation of a composition as an operator from spaces with mixed norm to Bloch $\alpha$-spaces, Mat. Sb. 199, 12 (2008), 117-128 (in Russian); English translation in Sb. Math. 199, 11-12 (2008), 1847-1857.

[9] S. LI, S. STEvić, Composition followed by differentiation between $H^{\infty}$ and $\alpha$-Bloch spaces, Houston J. Math. 35, 1 (2009), 327-340.

[10] S. Li, S. STEVIĆ, Products of integral-type operators and composition operators between Bloch-type spaces, J. Math. Anal. Appl. 349, 2 (2009), 596-610.

[11] S. Li, S. STEvić, Riemann-Stieltjes operators between $\alpha$-Bloch spaces and Besov spaces, Math. Nachr. 282, 6 (2009), 899-911.

[12] S. Li, S. STEVIĆ, Products of composition and differentiation operators from Zygmund spaces to Bloch spaces and Bers spaces, Appl. Math. Comput. 217, 7 (2010), 3144-3154.

[13] S. LI, S. STEVIĆ, Generalized weighted composition operators from $\alpha$-Bloch spaces into weightedtype spaces, J. Inequal. Appl. 2015, 2015:265, 12 pp.

[14] S. Li, S. STEVIĆ, Weighted differentiation composition operators from the logarithmic Bloch space to the weighted-type space, An. Stiint. Univ. "Ovidius" Constanta Ser. Mat. 24, 3 (2016), 223-240.

[15] Y. LiAng, Z. ZHOU, New estimate of essential norm of composition followed by differentiation between Bloch-type spaces, Banach J. Math. Anal. 8, 1 (2014), 118-137.

[16] Y. LiU, Y. YU, On a Stević-Sharma operator from Hardy spaces to the logarithmic Bloch spaces, J. Inequal. Appl., (2015) 2015:22, DOI 10.1186/s13660-015-0547-1.

[17] Y. LIU, Y. YU, Products of composition, multiplication and radial derivative operators from logarithmic Bloch spaces to weighted-type spaces on the unit ball, J. Math. Anal. Appl. 423, 1 (2015), 76-93. 
[18] Y. LIU, Y. Yu, On an extension of Stević-Sharma operator from the general space to weighted-type spaces on the unit ball, Complex Anal. Oper. Theory 11, 2 (2017), 261-288.

[19] Y. LiU, X. LIU, AND Y. YU, On an extension of Stević-Sharma operator from the mixed-norm space to weighted-type spaces, Complex Variables and Elliptic Equations: An International Journal, 62, 5 (2017), 670-694.

[20] K. Madigan, A. Matheson, Compact composition operator on the Bloch space, Trans. Amer. Math. Soc. 347, 7 (1995), 2679-2687.

[21] A. MONTES-RodRÍGUEZ, Weighted composition operators on weighted Banach spaces of analytic functions, J. London Math. Soc. (2) 61, 3 (2000), 872-884.

[22] S. OHNo, Products of composition and differentiation between Hardy spaces, Bull. Austral. Math. Soc. 73, 2 (2006), 235-243.

[23] B. Sehba, S. Stević, On some product-type operators from Hardy-Orlicz and Bergman-Orlicz spaces to weighted-type spaces, Appl. Math. Comput. 233, (2014), 565-581.

[24] S. STEVić, Norm of weighted composition operators from Bloch space to $H_{\mu}^{\infty}$ on the unit ball, Ars Combinatoria 88, (2008), 125-127.

[25] S. STEVIĆ, Norm and essential norm of composition followed by differentiation from $\alpha$-Bloch spaces to $H_{\mu}^{\infty}$, Appl. Math. Comput. 207, 1 (2009), 225-229.

[26] S. STEVIĆ, On a new integral-type operator from the Bloch space to Bloch-type spaces on the unit ball, J. Math. Anal. Appl. 354, 2 (2009), 426-434.

[27] S. STEVIĆ, On an integral-type operator from logarithmic Bloch-type and mixed-norm spaces to Bloch-type spaces, Nonlinear Anal. TMA71, 12 (2009), 6323-6342.

[28] S. STEVIĆ, Products of composition and differentiation operators on the weighted Bergman space, Bull. Belg. Math. Soc. Simon Stevin 16, 4 (2009), 623-635.

[29] S. STEVIĆ, Weighted differentiation composition operators from mixed-norm spaces to weighted-type spaces, Appl. Math. Comput. 211, 1 (2009), 222-233.

[30] S. Stević, Composition followed by differentiation from $H^{\infty}$ and the Bloch space to $n$th weightedtype spaces on the unit disk, Appl. Math. Comput. 216, 12 (2010), 3450-3458.

[31] S. STEVIĆ, On an integral operator between Bloch-type spaces on the unit ball, Bull. Sci. Math. 134, 4 (2010), 329-339.

[32] S. STEVIĆ, On operator $P_{\Phi}^{g}$ from the logarithmic Bloch-type space to the mixed-norm space on the unit ball, Appl. Math. Comput. 215, 12 (2010), 4248-4255.

[33] S. STEvić, Weighted differentiation composition operators from $H^{\infty}$ and Bloch spaces to $n$th weighted-type spaces on the unit disk, Appl. Math. Comput. 216, 12 (2010), 3634-3641.

[34] S. STEVIĆ, Weighted differentiation composition operators from the mixed-norm space to the $n$th weighted-type space on the unit disk, Abstr. Appl. Anal. 2010, Art. ID 246287, 15 pp.

[35] S. STEVIĆ, Characterizations of composition followed by differentiation between Bloch-type spaces, Appl. Math. Comput. 218, 8 (2011), 4312-4316.

[36] S. STEVIĆ, Essential norm of some extensions of the generalized composition operators between $k$ th weighted-type spaces, J. Inequal. Appl. 2017, Paper No. 220, 13 pp.

[37] S. SteVić AND A. K. Sharma, Iterated differentiation followed by composition from Bloch-type spaces to weighted BMOA spaces, Appl. Math. Comput. 218, 7 (2011), 3574-3580.

[38] S. Stević And A. K. Sharma, On a product-type operator between Hardy and $\alpha$-Bloch spaces of the upper half-plane, J. Inequal. Appl. 2018, Paper No. 273, 18 pp.

[39] S. STEVić, A. K. Sharma AND A. Bhat, Essential norm of products of multiplication composition and differentiation operators on weighted Bergman spaces, Appl. Math. Comput. 218, 6 (2011), 23862397.

[40] S. Stević, A. K. Sharma And A. Bhat, Products of multiplication, composition and differentiation operators on weighted Bergman space, Appl. Math. Comput. 217, 20 (2011), 8115-8125.

[41] M. TJANI, Compact composition operators on some Möbius invariant Banach spaces, Doctoral Dissertation, Michigan State University, ISBN: 978-0591-27288-8, 68 pages (1996).

[42] Y. YU, Y. LIU, On Stević type operator from $H^{\infty}$ space to the logarithmic Bloch spaces, Complex Anal. Oper. Theory 9, 8 (2015), 1759-1780.

[43] H. Wulan, D. Zheng, AND K. ZHU, Compact composition operators on BMOA and the Bloch space, Proc. Amer. Math. Soc. 137, 11 (2010), 3861-3868.

[44] F. Zhang, Y. LiU, On the compactness of the Stević-Sharma operator on the logarithmic Bloch spaces, Math. Inequal. Appl. 19, 2 (2016), 625-642.

[45] F. ZHANG, Y. LiU, On a Stević-Sharma operator from Hardy spaces to Zygmund-type spaces on the unit disk, Complex Anal. Oper. Theory 12, 1 (2018), 81-100.

[46] J. ZHOU AND Y. LIU, Products of radial derivative and multiplication operators from $F(p, q, s)$ to 
weighted-type spaces on the unit ball, Taiwanese J. Math. 17, 1 (2013), 161-178.

[47] J. ZHOU AND X. ZHU, Product of differentiation and composition operators on the logarithmic Bloch space, J. Inequal. Appl. 2014, 2014:453, DOI 10.1186/1029-242X-2014-453.

[48] K. ZHU, Operator Theory in Function Space, Marcel Dekker, New York, 1990.

[49] K. ZHU, Analytic Besov spaces, J. Math. Anal. Appl. 157, 2 (1991), 318-336. 